Chronic Obstructive Pulmonary Diseases: Journal of the COPD Foundation

\author{
Original Research
}

\title{
Normal Routine Spirometry Can Mask COPD/Emphysema in Symptomatic Smokers
}

Arthur F. Gelb, $\mathrm{MD}^{1}$ Alfred Yamamoto, $\mathrm{MD}^{2}$ Eric K. Verbeken, $\mathrm{MD}^{3}$ James C. Hogg, MD, $\mathrm{PhD}{ }^{4}$

Donald P. Tashkin, MD ${ }^{5}$ Diem N. T. Tran, BA ${ }^{6}$ Roxanna M. Moridzadeh, BA, PA-C ${ }^{6}$ Christine Fraser, CPFT, RT Mark J. Schein, $\mathrm{MD}^{7}$ Marc Decramer, MD, PhD ${ }^{8}$ Eric F. Glassy, MD ${ }^{9}$ Jay A. Nadel, MD ${ }^{10}$

\begin{abstract}
Background: Recent studies have emphasized the difficulty of early detection of chronic obstructive pulmonary disease (COPD) in symptomatic smokers with normal routine spirometry. This includes post-bronchodilator normal forced expiratory volume in 1 second ( $\left.F E V_{1}\right)(\mathrm{L}) \geq 80 \%$ predicted, forced vital capacity (FVC) (L) $\geq 80 \%$ predicted, and $\mathrm{FEV}_{1} / \mathrm{FVC} \geq 70 \%$ or greater than age corrected lower limit of normal (LLN). However, in COPD the pathologic site of small airway obstruction and emphysema begins in the small peripheral airways $\leq 2 \mathrm{~mm}$ id which normally contribute $<20 \%$ of total airway resistance.

Methods: Expiratory airflow at high and low lung volumes post-bronchodilator were measured and correlated with lung computed tomography (CT) and lung pathology (6 patients) in 16 symptomatic, treated smokers, and all with normal routine spirometry.

Results: Despite normal routine spirometry, all 16 patients had isolated, abnormal forced expiratory flow at $75 \%$ of FVC (FEF 75 ) using data from Knudson et al, Hankinson et al NHAMES III, and Quanjer et al and the Global Lung Function Initiative. This reflects isolated detection of small airways obstruction and/or emphysema. Measuring airflow at $\mathrm{FEF}_{50}$ detected only 8 of 16 patients, maximal expiratory flow at $25 \%-75 \%$ of FVC $\left(\mathrm{MEF}_{25-75}\right)$ only 4 of 16 , residual volume (RV) 4 of 16 , and RV to total lung capacity ratio only 2 of 16 . There was excellent correlation between limited lung pathology and lung CT for absence of emphysema.

Conclusions: This study confirms our earlier observations that detection of small airways obstruction and/or emphysema, in symptomatic smokers with normal routine spirometry, requires analysis of expiratory airflow at low lung volumes, including $\mathrm{FEF}_{75}$. Dependence upon normal routine spirometry may result in clinical and physiologic delay in the diagnosis and treatment in symptomatic smokers with emphysema and small airways obstruction.
\end{abstract}

\footnotetext{
Abbreviations: forced expiratory volume in 1 second, FEV $\mathbf{1}$; lower limit of normal, LLN; computed tomography, CT; forced expiratory flow, FEF; maximal expiratory flow, MEF; residual volume, RV; American Thoracic Society, ATS; European Respiratory Society, ERS; SubPopulations and InteRmediate Outcome Measures In COPD, SPIROMICS; COPD Assessment Test, CAT; high resolution computed tomography, HRCT; National Health and Nutrition Examination Survey, NHANES; diffusing capacity corrected for alveolar volume, DLCO/V $\mathbf{A ( L )}$; maximal midexpiratory airflow, MMEF; total lung capacity, TLC; specific airway conductance, $\mathbf{s} \mathbf{G}_{\mathbf{A w}}$; maximal expiratory flow-volume, $\mathbf{M E F V}$

Funding Support: None

Date of Acceptance: October 22, 2020 | Published Online Date: December 11, 2020

Citation: Gelb AF, Yamamoto A, Verbeken EK, et al. Normal routine spirometry can mask COPD and emphysema in symptomatic smokers. Chronic Obstr Pulm Dis. 2021;8(1):124-134. doi: https://doi.org/10.15326/jcopdf.2012.0176
}

1 Pulmonary Division, Department of Medicine, Lakewood Regional Medical Center, Lakewood, California, United States and David Geffen School of Medicine at University of CaliforniaLos Angeles Health Sciences, Los Angeles, California, United States
2 Department of Pathology, Lakewood Regional Medical Center, Lakewood, California, United States

3 Department of Pathology, Katholieke Univeritair Ziekenhuis Gasthuisberg, Leuven, Belgium 
4 University of British Columbia James Hogg Research Centre, St. Paul's Hospital Vancouver, British Columbia, Canada

5 Division of Pulmonary and Critical Care Medicine, David Geffen School of Medicine at University of California-Los Angeles Health Sciences, Los Angeles, California, United States

6 Independent pulmonary function investigator, Lakewood, California, United States

7 Department of Radiology, Lakewood Regional Medical Center, Lakewood, California, United States

8 Department of Clinical and Experimental Medicine, Katholieke Univeritair Leuven-University of Leuven and University

Hospitals Leuven, Leuven, Belgium

9 Affiliated Pathologists Medical Group, Rancho Dominguez, California, United States

10Cardiovascular Research Institute and Departments of Medicine, Physiology, and Radiology, School of Medicine, University of California San Francisco, San Francisco, California, United States

\section{Address correspondence to:}

Arthur F. Gelb MD

3650 E. South St., Suite 308

Lakewood, Calif. 90712

Phone: (562)565-5333

Email: afgelb@msn.com

\section{Keywords:}

COPD; chronic obstructive pulmonary disease; emphysema; small airways obstruction; spirometry; forced expiratory flow at $75 \%$ of FVC; FEF $_{75}$

\section{This article contains an online supplement.}

\section{Introduction}

Normal and preserved routine spirometry can mask chronic obstructive pulmonary disease (COPD) and emphysema in symptomatic smokers who have abnormal expiratory airflow at forced expiratory flow(FEF) at $75 \%$ of the forced vital capacity $\left(\mathrm{FEF}_{75}\right)$. Guidelines for the initial detection of COPD, developed by the American College of Physicians, American College of Chest Physicians, American Thoracic Society(ATS), and the European Respiratory Society (ERS), all recommend the presence of respiratory symptoms. ${ }^{1}$ Furthermore, there has been increasing interest in earlier detection of COPD in symptomatic smokers. ${ }^{2-6}$ Woodruff et $\mathrm{al}^{2}$ reported results from the SubPopulations and InteRmediate Outcome Measures In COPD (SPIROMICS) study that approximately $50 \%$ of former or current symptomatic smokers with COPD, and an abnormal COPD Assessment Test ${ }^{7}$
(CAT) $>10$ had "preserved pulmonary function." This was based on post-bronchodilator forced expiratory volume in 1 second $\left(\mathrm{FEV}_{1}\right)$ to forced vital capacity (FVC) ratio $\geq 70 \%$ and $F V C(L)>80 \%$ predicted, and both also above the lower limit of normal (>LLN). Therapeutic intervention during the 3 months before enrollment in the study noted $42 \%$ having used inhaled bronchodilators and 23\% inhaled glucocorticoids. It was reported that $33 \%$ of the cohort had chronic bronchitis based on $\mathrm{CAT}^{7} 43 \%$ had been previously diagnosed with COPD, and $27 \%$ with asthma. ${ }^{2}$ The prospective rate of exacerbation was also higher among these individuals compared to both healthy nonsmokers, and current and former smokers with preserved spirometry and lower CAT scores. ${ }^{7}$ Thin section lung high resolution computed tomography (HRCT) was consistent with minimal if any emphysema, but mild thickening of airway walls were noted by Martinez et al. ${ }^{2,4}$ In a similar COPD Genetic Epidemiology study, Regan et al ${ }^{5}$ reported a higher incidence of emphysema in lung HRCT in symptomatic smokers, also with similar "preserved pulmonary function" studies as noted above., ${ }^{2,4}$ Bowler et $\mathrm{al}^{6}$ also emphasized increased COPD exacerbations in an outcome study from a similar cohort. The designation of normal or "preserved" spirometry including FEV 1 (L), FVC (L) and FEV 1 / FVC\% ignores the potential presence of isolated abnormal expiratory airflow limitation at lower lung volumes. This is consistent with intrinsic obstruction in small airways without cartilage, upstream from 10-12 divisions, with normal diameter $\leq 2.0 \mathrm{~mm}$, and /or emphysema. These physiologic observations have been recently emphasized by Hoesterey et al. ${ }^{8}$ The goal of the current study was to confirm our previous observations that detection of small airways obstruction and/or emphysema, in symptomatic smokers despite normal routine spirometry, requires analysis of expiratory airflow at low lung volumes, including $\mathrm{FEF}_{75}$.

\section{Materials and Methods}

\section{Study Population}

We initially selected 16 symptomatic patients over 18 months, and 5 were subsequently seen over $2-5$ years. All 16 patients, post $270 \mu \mathrm{g}$ inhaled aerosolized albuterol sulfate, had initial spirometry values greater than predicted $L L N$ and $\mathrm{FEV}_{1}(\mathrm{~L}) \geq 80 \%$ predicted in 
15 cases, and FVC(L) $\geq 80 \%$ predicted and $\mathrm{FEV}_{1} /$ FVC $\geq 70 \%$ in all 16 Cases. They were originally referred for further evaluation and management of suspected COPD, including either small airways obstruction and/or emphysema. They had variable complaints of shortness of breath, cough, wheezing, chest tightness, and $\mathrm{CAT}^{7}$ scores $>10$. Seven of the 16 patients also had a non-calcified lung nodule $<12 \mathrm{~mm}$ diameter detected on lung HRCT. There was no evidence for cardiac decompensation or other comorbidities and smoking history was from 30-75 pack years. Six of 16 patients were current smokers when initially seen and subsequently quit within 4 months. These 16 symptomatic patients were started on varying combinations of inhaled corticosteroids, short- and long-acting beta2-agonists, and/or muscarinic receptor antagonists for relief of symptoms. Pulmonary function studies were performed consistent with ATS/ERS recommendations. ${ }^{9}$ Predicted normal values included: spirometry before and after $270 \mu \mathrm{g}$ inhaled aerosolized albuterol sulfate administered using a space chamber from Morris et al, ${ }^{10}$ maximal inspiratory and expiratory flow-volume curves for FEF at $50 \%$ and $75 \%$ of FVC from Knudson et al, ${ }^{11}$ National Health and Nutrition Examination Survey (NHANES) III routine spirometry data from Hankinson et al, ${ }^{12}$ single breath diffusing capacity from Burrows et al, ${ }^{13}$ and static lung volumes measured by volume plethysmography from Goldman et al. ${ }^{14}$ Normal data for specific airway conductance was obtained from Zarins et al. ${ }^{15}$ Whole-lung thoracic HRCT without IV contrast was obtained at peak inspiration in all 16 cases, and technically included high-resolution, thin-section ( $1 \mathrm{~mm}$ ) lung slices, $0.8 \mathrm{~mm}$ slice spacing, Toshiba standard kernel FC 18, sharp kernel 52, and pitch 0.8-1.0, and Siemens sharp kernel B35.

All 7 patients with suspicious non-calcified lung nodules underwent surgical resection for suspected lung cancer. One patient (case 4) underwent wedge resection right lower lobe, 3 patients (cases 9-11) underwent wedge resection of the left lower lobe, 1 patient (case 7) underwent lobar resection of the left upper lung, 1 patient (case 8) underwent a right lower lobectomy and 1 patient (case 14) underwent a right middle lobectomy. This provided formalin non-inflated lung specimens for potential limited pathologic identification of extent of emphysema and small airways disease and for correlation with whole-lung CT in 6 of 7 cases. Inadequate lung tissue prevented emphysema scoring in Case 4.

In determining the extent of whole-lung emphysema on inspiratory lung HRCT, we divided both the right and left lungs into 3 zones each (total 6 zones). The upper zone is above the carina, the mid zone extends from the carina to the inferior pulmonary veins and the lower zone extends further below. We have relied on the classic Thurlbeck et al air inflated lung standards for scoring extent and severity of emphysema as adopted for lung $\mathrm{CT},{ }^{16}$ and based on our correlative structure-function studies. ${ }^{17,18}$ If the zonal extent of emphysema was $1 \%-25 \%$, it was considered minimal to mild, $26 \%-50 \%$ moderate, $51 \%-75 \%$ severe, and $>75 \%$ very severe. The HRCT whole-lung emphysema score was determined by author MJS based on our previous studies. ${ }^{17,18}$ The microscopic distance between 100 to 107 alveolar walls ( $\mathrm{Lm}$ ) was measured in 6 surgical cases by author EKV. Predicted mean value for $\mathrm{Lm}=0.0011^{\mathrm{x}}$ age (year) +0.2174 and normal value to $120 \%$ predicted exclude emphysema. ${ }^{19}$ Current data in this study has not been previously reported and informed consent was obtained from every patient included in the present study. The study was approved by the Western Institutional Review Board,

Olympia, Washington, (Protocol 20172049; NCT Registration Number 00576069).

\section{Results}

In the Tables 1-2 and in Figures 1-16 (in the online supplement), are results of pulmonary function studies post inhaled $270 \mu \mathrm{g}$ albuterol and lung HRCT in 16 cases, and lung pathology in 6 cases. The FVC was $>80 \%$ predicted in every case and the ratio of $\mathrm{FEV}_{1} / \mathrm{FVC} \geq 0.70 \%$ in all 16 cases. $\mathrm{FEV}_{1}$ was $>80 \%$ predicted in 15 cases but $>$ than LLN in all. Functional residual capacity and calculated total lung capacity (TLC) were all normal. In 8 of 16 cases, the diffusing capacity corrected for alveolar volume (DLCO/ $\left.\mathrm{V}_{\mathrm{A}(\mathrm{L})}\right)$ was abnormal, implying there was loss of integrity of the alveolar capillary surface area as in emphysema. Specific airway conductance was abnormal $<60 \%$ predicted in 11 of 16 cases. ${ }^{15}$ Maximal expiratory airflow (MEF) at 50\% expired FVC was abnormal in 10 of 16 cases, whereas at $75 \%$ expired FVC, FEF 75 was abnormal in all 16 cases, according to Knudsen et al, ${ }^{11}$ NHANES III, Hankinson et al, ${ }^{12}$ and Quanjer 
Table 1. Results of Pulmonary Function in 16 Cases

\begin{tabular}{|c|c|c|c|c|c|c|c|c|c|c|c|}
\hline \multicolumn{2}{|c|}{ CASE } & $\begin{array}{l}\text { FVC (L) } \\
\text { (\% pred) }\end{array}$ & $\begin{array}{l}\text { FEV } 1(\mathrm{~L}) \\
\text { (\% pred) }\end{array}$ & $\begin{array}{c}\mathrm{FEV}_{1 /} \\
\mathrm{FVC} \\
\%\end{array}$ & $\begin{array}{l}\text { TLC }(\mathrm{L}) \\
\text { (\% pred) }\end{array}$ & $\begin{array}{c}\text { DLCO/ } \\
V_{\mathrm{A}(\mathrm{L})} \\
(\% \text { pred })\end{array}$ & $\begin{array}{c}\mathrm{sG}_{\mathrm{AW}} \mathrm{L} / \mathrm{sec} / \\
\mathrm{cmH} \mathrm{2O} / \mathrm{L} \\
\text { (\% pred) }\end{array}$ & $\begin{array}{l}\text { FLOW 50\% } \\
\text { FVC (L/s) } \\
\text { (\% pred) }\end{array}$ & $\begin{array}{c}\text { FLOW } \\
75 \% \text { FVC } \\
\text { (L/s) } \\
\text { (\%pred) }\end{array}$ & $\begin{array}{c}\text { RV } \\
\text { (\% pred) }\end{array}$ & $\begin{array}{c}\text { RV/TLC\% } \\
\text { (\% pred) }\end{array}$ \\
\hline \multirow[t]{2}{*}{1} & $67 \mathrm{yrM}$ & $3.8(107)$ & $2.9(103)$ & 75 & $6.5(112)$ & $2.6(71)$ & $0.06(30)$ & $3.3(60)$ & $0.7(28)$ & 2.6(114) & 40(100) \\
\hline & 76yrM & $3.3(100)$ & $2.3(90)$ & 77 & $6.1(108)$ & $2.8(81)$ & $0.06(30)$ & $1.6(30)$ & $0.4(41)$ & $2.4(100)$ & $39(93)$ \\
\hline \multirow[t]{2}{*}{2} & $80 \mathrm{yr}$ & $3.4(95)$ & $1.9(77)$ & 57 & $5.9(90)$ & $3.1(81)$ & $0.12(64)$ & $1.0(20)$ & $0.3(30)$ & $2.5(91)$ & 43(96) \\
\hline & $81 \mathrm{yr}$ & $3.5(100)$ & $1.8(73)$ & 51 & $5.8(88)$ & $2.8(74)$ & $0.05(29)$ & $0.6(20)$ & $0.2(20)$ & $2.3(82)$ & 43(96) \\
\hline \multirow{3}{*}{3} & $69 y r M$ & $3.6(103)$ & $2.6(94)$ & 72 & $5.6(96)$ & $2.8(77)$ & $0.15(71)$ & $2.2(51)$ & $0.4(35)$ & $1.9(84)$ & $34(85)$ \\
\hline & $72 \mathrm{yr}$ & $3.7(109)$ & $2.9(100)$ & 72 & $6.1(105)$ & $2.8(78)$ & $0.18(84)$ & $2.8(64)$ & $0.4(40)$ & $2.2(94)$ & $37(90)$ \\
\hline & $78 \mathrm{yrM}$ & $2.7(87)$ & $2.1(88)$ & 78 & $5.5(100)$ & $4.2(122)$ & $0.15(68)$ & $1.6(34)$ & $0.4(40)$ & $2.3(98)$ & 42(95) \\
\hline \multirow[t]{2}{*}{4} & $81 \mathrm{yr}$ & 3.0(99) & $1.8(77)$ & 77 & $5.2(96)$ & $3.5(105)$ & $0.08(34)$ & $1.0(24)$ & $0.3(30)$ & $2.1(96)$ & 40(91) \\
\hline & $83 \mathrm{yr}$ & $3.3(114)$ & 1.8 (92) & 56 & $5.4(91)$ & 3.8(95) & $0.08(34)$ & $1.2(30)$ & $0.3(32)$ & $2.1(95)$ & 39(89) \\
\hline 5 & $80 y r M$ & $4.0(83)$ & $2.8(81)$ & 71 & $6.3(83)$ & $1.9(57)$ & $0.09(39)$ & $2.3(43)$ & $0.3(21)$ & $1.8(58)$ & 29(71) \\
\hline \multirow{2}{*}{6} & $84 y r F$ & 2.3(105) & $2.0(125)$ & 87 & $5.0(115)$ & $2.1(65)$ & $0.14(64)$ & $1.4(35)$ & $0.2(10)$ & 2.3(126) & $46(104)$ \\
\hline & $89 y r$ & $2.6(136)$ & $1.9(134)$ & 72 & $4.9(108)$ & $2.5(62)$ & $0.17(77)$ & $2.0(50)$ & $0.2(12)$ & $2.2(122)$ & $45(100)$ \\
\hline 7 & $81 \mathrm{yrM}$ & $4.2(100)$ & $3.0(92)$ & 71 & $7.4(108)$ & $2.9(86)$ & $0.13(55)$ & $2.5(47)$ & $0.7(30)$ & $3.0(46)$ & $41(100)$ \\
\hline 8 & $75 \mathrm{yrF}$ & $2.8(113)$ & $2.0(104)$ & 71 & $4.9(117)$ & $1.8(51)$ & $0.09(36)$ & $1.1(27)$ & $0.4(19)$ & 2.1(123) & 43(86) \\
\hline 9 & $59 y r F$ & $2.6(85)$ & $2.0(82)$ & 78 & $4.9(100)$ & 4.0(103) & $0.15(61)$ & $2.3(52)$ & $0.6(27)$ & $1.8(99)$ & $37(100)$ \\
\hline 10 & $61 \mathrm{yrM}$ & $3.1(97)$ & $2.5(97)$ & 80 & $5.1(98)$ & $3.9(101)$ & $0.11(53)$ & $2.9(53)$ & $0.9(34)$ & $1.6(80)$ & $31(84)$ \\
\hline 11 & $82 \mathrm{yrM}$ & $3.8(116)$ & $2.8(122)$ & 73 & $5.1(95)$ & $2.3(68)$ & $0.21(97)$ & $2.8(53)$ & $0.6(25)$ & $1.1(44)$ & 22(96) \\
\hline \multirow{3}{*}{12} & $69 \mathrm{yrF}$ & $2.3(86)$ & $1.7(81)$ & 74 & $4.2(94)$ & $1.8(51)$ & $0.08(31)$ & $1.3(30)$ & $0.3(43)$ & $1.2(67)$ & 29(71) \\
\hline & $72 \mathrm{yr}$ & $2.9(112)$ & $1.4(69)$ & 49 & $5.4(124)$ & $2.2(62)$ & $0.06(24)$ & $0.8(20)$ & $0.2(27)$ & $2.5(141)$ & $46(121)$ \\
\hline & $60 \mathrm{yrM}$ & 4.6(82) & 3.4(76) & 74 & $8.0(102)$ & $3.0(78)$ & $0.06(27)$ & $2.0(40)$ & $0.7(32)$ & $2.5(92)$ & $31(84)$ \\
\hline \multirow[t]{2}{*}{13} & $62 \mathrm{yr}$ & $5.0(92)$ & 3.2(72) & 64 & 7.7(98) & $3.8(92)$ & $0.08(32)$ & $2.0(40)$ & $0.5(23)$ & $2.6(100)$ & 37(95) \\
\hline & $64 \mathrm{yr}$ & $5.2(94)$ & $3.2(76)$ & 60 & 8.3(101) & $3.2(85)$ & $0.12(50)$ & $1.9(37)$ & $0.4(18)$ & $3.1(114)$ & 35(92) \\
\hline 14 & $76 y r F$ & $2.1(84)$ & 1.5(84) & 75 & $4.7(112)$ & $2.0(57)$ & $0.11(43)$ & $1.4(35)$ & $0.5(21)$ & 2.3(134) & $52(130)$ \\
\hline 15 & 77yrF & $2.5(89)$ & $1.8(88)$ & 71 & 5.1(99) & 3.3(95) & $0.13(51)$ & $2.1(52)$ & $0.5(21)$ & $2.6(122)$ & 51(121) \\
\hline \multirow[t]{4}{*}{16} & $60 \mathrm{yrF}$ & $3.9(106)$ & $2.5(92)$ & 70 & 4.9(101) & $1.8(46)$ & $0.22(84)$ & $1.9(44)$ & $0.5(24)$ & $1.9(102)$ & 39(105) \\
\hline & Mean & $3.2 \pm 0.8$ & $2.4 \pm 0.5$ & $74 \pm 5$ & $5.6 \pm 1.0$ & $2.7 \pm 0.8$ & $0.12 \pm 0.05$ & $2.0 \pm 0.6$ & $0.5 \pm 0.2$ & $2.1 \pm 0.6$ & $38 \pm 9 \%$ \\
\hline & $\pm \mathrm{SD}$ of & $(96 \pm 11)$ & $(93 \pm 14)$ & & $(103 \pm 9)$ & $(76 \pm 21)$ & $(52 \pm 20)$ & $(43 \pm 10)$ & $(23 \pm 6)$ & $97 \pm 25 \%$ & $95 \pm 16 \%$ \\
\hline & Initial & $0 / 16$ & $0 / 16$ & $0 / 16$ & $0 / 16$ & $8 / 16$ & $11 / 16$ & $10 / 16$ & $16 / 16$ & $4 / 16$ & $2 / 16$ \\
\hline
\end{tabular}

Data

\section{Only}

Results of FVC, FEV1, TLC (total lung capacity when functional residual capacity obtained in volume plethysmograph), DLCO/VA(L), $\mathrm{sG}_{\mathrm{AW}}$, and flow calculated at $50 \%$ and $75 \%$ of forced expired volume (see Figures in the online supplement for MEFV curve). Initial routine spirometry and TLC were normal in all 16 cases with observed values $\geq$ predicted LLN. DLCO/VA was abnormal in 7 cases, sG $\mathrm{V}_{A \mathrm{~W}}$ abnormal in 8 cases, abnormal expired flow at 50\% FVC in 8 cases and at $75 \%$ of expired volume on MEFV curve abnormal in all 16 cases. However, maximal flow from $25 \%-75 \%$ expired volume on MEFV curve was abnormal in only 4 cases. Lung HRCT Thurlbeck emphysema scores 16 in 6 surgical patients demonstrated excellent correlation with inflated lung emphysema scores 19 in all 6 Cases. $\mathrm{DLCO} / \mathrm{V}_{\mathrm{A}(\mathrm{L})}$ was abnormal in 3 of 6 Cases with limited surgical lung pathology (Cases 7-11,14), that revealed no emphysema (see Figures in the online supplement) or evidence of bronchiolar abnormalities. There was inadequate lung tissue for analysis in surgical Case 4. Serial data over time was obtained in Cases 2,3,4,12 and 13. Note that 5 patients had lung function studies measured on two separate occasions up to 5 years apart.

$\mathrm{FVC}=$ forced vital capacity; $\mathrm{FEV}_{1}=$ forced expiratory volume in 1 second; TLC=total lung capacity; $\mathrm{DLCO} / \mathrm{V}_{\mathrm{A}(\mathrm{L})=\text { diffusing capacity/alveolar }}$ volume; $\mathrm{sG}_{\mathrm{AW}}=$ specific airway conductance; $\mathrm{RV}=$ residual volume; $\mathrm{MEFV}=$ maximal expiratory flow-volume; LLN=lower limit of normal; HRCT=high resolution computed tomography

et $\mathrm{al}^{20}$ predicted mean minus $1.64 \mathrm{SD}$ (see Figures 1-16 in the online supplement which correspond to Cases 1-16 in Table 1 and Table 2). Maximal midexpiratory airflow (MMEF $25-75)$ was abnormal in only
4 of 16 cases, ${ }^{11,12}$ increased residual volume (RV) in 4 cases, and RV/TLC\% in only 2 cases. Wholelung CT emphysema scoring as noted in the tables and the figures (in the online supplement) in 9 


\section{Table 2. Results of COPD Assessment Test Score, Lung Computed Tomography, Pathology and Emphysema Scores in 16 Cases}

\begin{tabular}{|c|c|c|c|c|c|c|}
\hline CASE & $\begin{array}{l}\text { CAT } \\
\text { Score }^{7} \\
\text { Pre/Post } \\
\text { Therapy }\end{array}$ & $\begin{array}{c}\text { Lung CT } \\
\text { Bronchiectasis }\end{array}$ & $\begin{array}{l}\text { Alveolar } \\
\text { Intersections } \\
\text { Lm (mm) } \\
(\% \text { pred })^{19}\end{array}$ & $\begin{array}{l}\text { Pathology of } \\
\text { Small Airway } \\
\text { Bronchioles }\end{array}$ & $\begin{array}{c}\text { Lung CT } \\
\text { Thurlbeck } \\
\text { Emphysema } \\
\text { Score }^{16}\end{array}$ & $\begin{array}{c}\text { Surg Path } \\
\text { Thurlbeck } \\
\text { Emphysema } \\
\text { Score }^{19}\end{array}$ \\
\hline 1 & $14 / 10$ & mild & & & Moderate 30 & \\
\hline 2 & $14 / 10$ & 0 & & & Moderate 35 & \\
\hline 3 & $18 / 12$ & 0 & & & Moderate 30 & \\
\hline 4 & $18 / 12$ & 0 & & Insufficient lung tissue for evaluation & Moderate 45 & R lower lobe wedge \\
\hline 5 & $18 / 12$ & 0 & & & Moderate 45 & \\
\hline 6 & $14 / 10$ & 0 & & & Mild 15 & \\
\hline 7 & $14 / 10$ & 0 & $0.327(106)$ & $\begin{array}{l}\text { Chronic inflammation, smooth muscle } \\
\text { hyperplasia, chronic lymphocytic } \\
\text { inflammation }\end{array}$ & Normal 0 & 0 L upper lobectomy \\
\hline 8 & $14 / 10$ & 0 & $0.315(105)$ & Chronic lymphocytic inflammation & $\begin{array}{l}\text { Mild upper } \\
\text { lobes only } 15\end{array}$ & 0 R lower lobectomy \\
\hline 9 & $18 / 12$ & 0 & $0.322(114)$ & normal & Normal 0 & 0 L lower lobe wedge \\
\hline 10 & $18 / 12$ & mild & $0.306(107)$ & normal & Normal 0 & 0 L lower lobe wedge \\
\hline 11 & $18 / 12$ & mild & $0.327(106)$ & $\begin{array}{l}\text { Chronic inflammation, mucous cell } \\
\text { metaplasia and hyperplasia }\end{array}$ & Normal 0 & 0 L lower lobe wedge \\
\hline 12 & $18 / 12$ & 0 & & & Moderate 30 & \\
\hline 13 & $18 / 10$ & 0 & & & Mild 15 & \\
\hline 14 & $18 / 12$ & 0 & $0.306(102)$ & $\begin{array}{l}\text { Chronic inflammation, follicular } \\
\text { bronchiolitis }\end{array}$ & Normal 0 & 0 R middle lobectomy \\
\hline 15 & $18 / 12$ & 0 & & & Moderate 50 & \\
\hline 16 & $18 / 12$ & 0 & & & Mild 20 & \\
\hline
\end{tabular}

CAT $=$ COPD Assessment Test; $\mathrm{CT}=$ computed tomography

non-surgical resection cases ranged from mild in 4 cases, to moderate in 5 cases, with predominance in mid to upper lung zones. Whole lung HRCT in 7 surgical resection patients (cases 4, 7-11, and 14) suggested no emphysema in Cases $7,9,10,11$, and 14 , and mild emphysema only in the upper zone in Case 8 , and moderate emphysema in Case 4 based on our previous correlative studies. ${ }^{17.18}$ Moreover, in Case 8, lung resection RLL pathology confirmed the absence of emphysema, despite lung CT-scored mild emphysema, which was limited to upper lung zones. Inadequate lung tissue prevented pathologic emphysema scoring in Case 4. Corresponding lung pathology not shown was consistent with Stage 1 lung malignancy in all 7 surgically resected cases. There was no significant breakdown of alveolar attachments in lung tissue surrounding terminal bronchioles in the 6 patients studied (figures in the online supplement and Cases 7-11, and 14). Furthermore, the distance between 100-107 alveolar walls (Lm) was normal in every surgical case. In Case $7 \mathrm{Lm}=0.327 \mathrm{~mm} \mathrm{106 \%}$ predicted, in Case $8 \mathrm{Lm}=0.315 \mathrm{~mm} \mathrm{105 \%} \mathrm{predicted,}$ in Case $9 \mathrm{Lm}=0.322 \mathrm{~mm} \mathrm{114 \%} \mathrm{predicted,} \mathrm{in} \mathrm{Case} 10$ $\mathrm{Lm}=0.306 \mathrm{~mm} \mathrm{107 \%}$ predicted, in Case $11 \mathrm{Lm}=0.327$

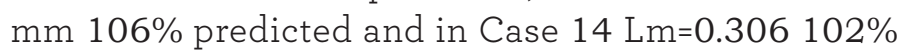
predicted. Emphysema was excluded microscopically in all 6 surgical cases evaluated. Bronchioles were morphologically within normal limits, and luminal diameters remained intact and comparable to luminal diameters of accompanying pulmonary arteries.

\section{Discussion}

The 16 cases of symptomatic smokers presented here provides further examples of patients with apparently "preserved spirometry" but symptoms consistent with COPD, as well as HRCT lung evidence of emphysema in 11 of the 16 cases. All had normal 
FEV $1, \mathrm{FEV}_{1} / \mathrm{FVC} \%$, and FVC. However, none of the patients had truly "preserved lung function," as indicated by the presence of variable abnormally low values of FEF rates at low lung volumes in all 16 cases. This also included a significant reduction in specific airway conductance ( $s G_{A w}$ ) in 11 of the 16 cases, and a significantly reduced DLCO/V $\mathrm{V}_{\mathrm{A}(\mathrm{L})}$ in 8 of the cases. Interestingly, despite significant reductions in $\mathrm{FEF}_{75}$ in all 16 cases, $\mathrm{MMEF}_{25-75}$ was abnormal in only a quarter of the cases. Eleven of the 16 cases had mild to moderate predominantly upper zone emphysema by systematic visual assessment. ${ }^{16-18}$ The absence of HRCT evidence of an emphysema score was confirmed by pathologic examination of inflated resected lung specimens in all 6 patients who underwent lobectomy or wedge resection and provided adequate material for pathology. The 5 patients without HRCT lung evidence of emphysema most likely had small airways disease without parenchymal involvement, although the HRCT lung images from these patients could not be systematically evaluated for evidence of small airways disease. Furthermore, lung HRCT images were obtained at TLC and not at RV.

\section{Overview: Historical and Current Perspective}

In an accompanying editorial referring to Woodruff et al, ${ }^{2}$ Fabbri $^{21}$ reiterated that patients with normal FVC, FEV 1 and $F E V_{1} / F V C \%$ do not fulfill the definition of COPD, by current COPD guidelines (GOLD). ${ }^{22}$ Moreover, Fabbri ${ }^{21}$ emphasized that COPD may be a disease of the "lungs quiet zone," as originally defined by Woolcock et al. ${ }^{23}$ This view was later expanded upon in an editorial by $\mathrm{Mead}^{24}$ almost 50 years ago: "a place where there can be pathologic changes that are not detected by changes in the FEV ". The editorial by Mead ${ }^{24}$ was in affirmation of 2 original articles identifying the pathophysiology of small airway disease. ${ }^{25,26}$ Sentinel pathophysiologic studies by Macklem and Mead ${ }^{27}$ demonstrated that the resistance offered by the peripheral, small airways without cartilage, upstream from 10-12 divisions, and $\leq 2.0 \mathrm{~mm}$ id, normally contributed $<20 \%$ of total airway resistance. Moreover, $\mathrm{Mead}^{24}$ and Hogg et al ${ }^{28}$ reported that in the presence of COPD, with or without emphysema, the distal quiet small bronchiolar zone was the major site of increased airway resistance. These studies were performed in post-mortem lung specimens, when the larynx was excluded. ${ }^{27,28}$ When all upper airways resistance is included, the contribution of small airways resistance to total airways resistance is probably $\leq 15 \%$. This paradigm could be further obscured by normal expiratory spirometry measurements consistent with "preserved pulmonary function" as previously reported. ${ }^{2-6}$

In the early 1970's, mentored by Jay A. Nadel, we published several sentinel pathophysiologic translational observations to help facilitate earlier detection of both subclinical emphysema ${ }^{29,30}$ and intrinsic small airway disease, including asthma in non-smokers. ${ }^{29-31}$ Despite the presence of normal routine spirometry, the physiologic diagnosis of suspected moderate-to-severe emphysema, was proven by pathology of resected lobe(s) for malignant lung nodules after air or formalin inflation. ${ }^{29,30}$ Furthermore, additional physiologic abnormalities obtained prior to lung surgery in suspected emphysema included the combination of abnormal diffusing capacity, loss of static lung elastic recoil, and abnormal expiratory airflow limited to the distal part of the maximal expiratory flow-volume (MEFV) curve at $80 \%$ expired FVC. However, mid-expiratory airflow rates, airway resistance and TLC remained normal. ${ }^{29-31}$

The MEFV curve was developed by Fry and Hyatt ${ }^{32}$ and was obtained simultaneously during volumetime spirometry. We emphasized the reproducibility of analyzing expiratory flow at $75 \%$ and $80 \%$ of expired FVC. ${ }^{29-31}$ Furthermore, intrinsic small airway abnormalities in non-smoking asthmatics with bronchiolar obstruction were similarly identified using MEFV curves, despite normal static lung elastic recoil, normal diffusing capacity, and normal routine spirometry. ${ }^{28-31}$ Abnormal expiratory airflow in the distal part of the MEFV curve, namely $\mathrm{FEF}_{75}$ was as sensitive as abnormal closing volume, extent of heliox isoflow, ${ }^{33}$ frequency dependence of dynamic lung compliance, and increased arterial-alveolar oxygen gradient. ${ }^{29-33}$ It should be further emphasized that expiratory airflow at any effort independent lung volume is directly related to the static lung elastic recoil pressure and inversely to the intrinsic airway resistance. ${ }^{34,35}$ When static lung elastic recoil pressure and expiratory flow are measured at identical effort independent lung volumes, it is relatively easy to determine the individual contribution of loss of lung elastic recoil versus peripheral intrinsic airway 
obstruction in limiting expiratory airflow. ${ }^{29-31,34,35}$ The structure-function studies by Cosio et al ${ }^{36}$ subsequently confirmed our initial physiologic observations in smokers with normal or borderline spirometry and diffusing capacity, and minimal or no emphysema. They could be separated from normal individuals by exhibiting an abnormal MEFV curve at mid lung volume, abnormal closing capacity, volume of isoflow, and phase 3 of the single-breath nitrogen washout. ${ }^{36}$ However, in the Cosio et al ${ }^{36}$ study, MEFV curves were not analyzed at low lung volumes. In a subsequent pathophysiology study, Hogg et $\mathrm{al}^{37}$ reported that smokers with GOLD Stage 0 with normal spirometry and GOLD Stage 1 with mild expiratory airflow limitation $\mathrm{FEV}_{1} / \mathrm{FVC} \leq 70 \%$ and $\mathrm{FEV}_{1} \geq 80 \%$ predicted, had mild thickening of the walls of small airways and accumulation of inflammatory mucous exudates in their lumen. In a more recent pathological study, McDonough et $\mathrm{al}^{38}$ reported that narrowing and disappearance of small conducting airways and destruction of terminal bronchioles occurred before the onset of overt emphysematous destruction and was probably responsible for the increased peripheral airway resistance in COPD. In a sentinel pathophysiologic study, Hogg et $\mathrm{al}^{39}$ reported that 10 of 54 (18.5\%) chronic smokers with localized lung cancer, despite $\mathrm{FEV}_{1}$ 100\%-110\% predicted, and normal static lung volumes, had diffusing capacity $81 \% \pm 18 \%$ predicted (mean $\pm S D$ ), and maximal midexpiratory flow $\mathrm{MMEF}_{25-75} 80 \% \pm 33 \%$ predicted, and Thurlbeck emphysema score $23 \pm 13$ (mean \pm SD) in resected lobes or lungs. ${ }^{15,19}$ When the FEV 1 was 90\%-99\% predicted, the prevalence of emphysema using Thurlbeck score $22 \pm 9$ was 33\% predicted, and diffusing capacity was $102 \% \pm 34 \%$ predicted, and $\mathrm{MMEF}_{25-75} 66 \% \pm 24 \%$ predicted. ${ }^{39}$ When the FEV 1 was between $80 \%-89 \%$ predicted, the prevalence of emphysema score $25 \pm 14$ was $33 \%$ and diffusing capacity was $83 \% \pm 26 \%$ predicted and $\mathrm{MMEF}_{25-75}$ $59 \% \pm 23 \%$ predicted. $^{39}$ Tan et al ${ }^{40}$ have recently reported that $11 \%$ of life-time never-smokers demonstrated emphysema on CT scans, and the prevalence increased to $30 \%$ among smokers despite normal lung function. Furthermore, Hogg, Pare, and Hackett have provided the interested reader with an in-depth review of the contribution of small airway obstruction to the pathogenesis of COPD and emphysema. ${ }^{41}$

Obstruction of small, peripheral airways $<2 \mathrm{~mm}$ id is the major site of pathophysiology in COPD. ${ }^{23-28,41}$ Because peripheral resistance is normally small, there may be considerable intrinsic obstruction in peripheral airways and/or emphysema that could affect ventilation distribution and gas exchange but would have little effect on lung function tests designed to detect expiratory airflow obstruction. When total airway resistance is elevated to a clinically recognized level in the small airways, obstruction is much more severe than is generally recognized. ${ }^{24,31,41}$ The NHANES III data reported by Stanojevic et al ${ }^{42}$ noted that median value for $\mathrm{FEV}_{1} / \mathrm{FVC} \%$ in healthy, non-smoking males, 40 years of age was $80 \%$ and lower limit of normal was $70 \%$, corresponding to 50 th percentile predicted. The median value for $\mathrm{FEV}_{1} /$ FVC\% in healthy males 60 years of age was $75 \%$ and LLN was $65 \%$, corresponding to 50 th percentile predicted. ${ }^{42}$ The median value for $\mathrm{FEV}_{1} / \mathrm{FVC}^{2}$ in healthy males 80 years of age was $72 \%$ and lower limit of normal was $57 \%$, also corresponding to 50 th percentile predicted. ${ }^{42}$ Values for $\mathrm{FEV}_{1} / \mathrm{FVC} \%$ in healthy females compared to males at the same age, were slightly greater by $2 \%{ }^{42}$ Moreover, these data emphasize the limitations of using FEV $1 / F V C<70 \%$ to identify potential expiratory airway obstruction in smokers 60 years of age and older. ${ }^{42}$ We also have emphasized that when the $F E V_{1} / F V C$ is equal or greater than $75 \%$, the $\mathrm{MMEF}_{25-75}$ is always normal. ${ }^{43}$ However, if $\mathrm{MMEF}_{25-75}$ is reduced, the $\mathrm{FEV}_{1} / \mathrm{FVC} \%$ is always less than $75 \%$, although not always outside predicted limits. ${ }^{43}$ Detection of mild COPD in presence of a normal $\mathrm{FEV}_{1} / \mathrm{FVC}$, using novel isolated spirometry reductions including $\mathrm{FEV}_{3} / \mathrm{FVC}, \mathrm{FEV}_{3} /$ $\mathrm{FEV}_{6}$ and $\mathrm{FEV}_{1} / \mathrm{FEV}_{6}$ have been proposed. ${ }^{4,45}$ However, in our 16 cases, only 3 cases could be identified as abnormal using these novel spirometry measurements. ${ }^{44,45}$ A normal diffusing capacity may be misleading, and not always detect mild to moderate emphysema observed on thoracic HRCT, as noted in 3 cases in the present study. We have previously noted normal diffusing capacity in never smoked, chronic asthmatics with persistent expiratory airflow limitation and measured loss of lung elastic recoil with a thoracic HRCT scan consistent with normal or mild emphysema. ${ }^{46}$ Subsequent autopsy and/or explanted whole lung when formalin is inflated confirmed mild to moderate emphysema. ${ }^{46}$

The current challenge is to more easily detect COPD, emphysema, and/or intrinsic small airway obstruction 
masked by otherwise "preserved pulmonary function," i.e., normal routine spirometry. This challenge is important in symptomatic smokers, ${ }^{2-6,29,30}$ and in symptomatic non-smoking asthmatics, ${ }^{31,46}$ and can be achieved by analyzing expiratory flow at low lung volumes on the MEFV curve ${ }^{29-31}$ using applicable reference values. ${ }^{10-12,42}$ However, it is important for the reader to acknowledge the 2017 ATS Technical Statement with recommendations for standardized pulmonary function studies. ${ }^{47}$ The original Global Lung Function Initiative (GLI) pre-albuterol "normal spirometry" data reported by Quanjer et $\mathrm{ll}^{48}$ was obtained in 15,661 presumably non-smoking individuals aged 3-94 years. They were referred for pulmonary function testing in Poland and the United States for clinical evaluation of asthma, cystic fibrosis, cough, dyspnea, and other miscellaneous clinical problems. Only $2.75 \%$ had an abnormal $\mathrm{FEF}_{25-75}$, and $1.29 \%$ an abnormal $\mathrm{FEF}_{75}$. Alternatively, despite normal routine spirometry, $\mathrm{FEF}_{25-75}$ remained abnormal in $2.9 \%$ of cases and $\mathrm{FEF}_{75}$ abnormal in $12.3 \%$ of cases. Based on these data, Quanjer et $\mathrm{al}^{48}$ and Lukic et $\mathrm{ll}^{49}$ and subsequently the $\mathrm{ATS}^{47}$ concluded that measuring expiratory flow at 25\%$75 \%$ and at $75 \%$ expired FVC had not demonstrated added value for identifying expiratory airflow obstruction in adults and children. ${ }^{49}$ Therefore, these tests were not recommended for routine use. This was based on epidemiologic and not clinical studies in symptomatic non-smokers. When using GLI normal data for spirometry including $\mathrm{FEF}_{75}$ (lps) from Quanjer et al, ${ }^{48}$ our results were similar to using reference normal data from Morris et al ${ }^{10}$ and Hankinson et al (NHAMES III). ${ }^{12}$ The findings presented here confirm our previous ${ }^{29-31}$ and other studies ${ }^{50-53}$ underscoring the value of further pursuing earlier detection of COPD in symptomatic patients, with normal "preserved" routine spirometry. Future investigations are needed to provide additional clinical data, including physiologic, wholelung thoracic HRCT, and when available, correlative pathologic evidence of underlying obstructive lung disease to challenge current recommendations regarding not analyzing expiratory flow at low lung volumes. ${ }^{47-49}$ We believe that clinicians need to reject the conclusion suggested by Sator and colleagues (BOLD study) ${ }^{54}$ that normal routine spirometry is consistent with a false positive clinical diagnosis of COPD in symptomatic patients with respiratory symptoms including in smokers. They never measured FEF 75. The accompanying editorial by Vanfleteren et al ${ }^{55}$ highlighted the complexity of making the correct diagnosis of COPD in symptomatic patients with normal routine spirometry. However, they ${ }^{55}$ did not acknowledge the importance of measuring expiratory airflow at low lung volumes, i.e., FEF for detection of unsuspected small airway obstruction and/or emphysema, especially in symptomatic smokers. ${ }^{29-31}$ Recent updates ${ }^{56,57}$ on earlier detection of COPD in symptomatic smokers with normal "preserved" routine spirometry have not further addressed the issue of analyzing expiratory airflow at lower lung volumes including $\mathrm{FEF}_{75}$. Moreover, the recent editorial by Barnes et $\mathrm{al}^{58}$ emphasized the pressing need to redefine symptomatic "GOLD 0 COPD".

\section{Acknowledgements}

Author contributions: AFG, JCH, JAN, AY, and EKV provided conception and design. Analysis and interpretation were provided by AFG, JCH, JAN, AY, MS, EKV, EFG, MD, and DPT. Intellectual contributions and drafting of the article were provided by AFG, JCH, JAN, AY, MS, EKV, EFG, MD, and DPT. DNTT, $R M M$, and $C F$ were responsible for the lung function studies. AY, JCH, EKV, and EFG were responsible for the pathology studies and MS was responsible for the radiology studies.

The authors thank pathologists Be Huynh, MD, from Long Beach Memorial Medical Center, Long Beach, California for Case 8 (Figure 8c,d) and Yuki Takasumi, MD, from Providence Saint John's Health Center, Santa Monica, California for Case 9 (Figure 9c,d), and thoracic surgeons Navrose Grewal MD, Robert J. McKenna, Jr., MD, and George Panagiotides, MD. The authors also thank graphic artist Janet Ward, Bob Ward, BS, MS, electrical engineering, and Richard F. Rideout, and Amanda Post for the lung function studies and Noe Zamel, MD, Pulmonary Division, Department of Medicine, University of Toronto, Ontario, Canada for the pulmonary physiologic discussion.

\section{Declaration of Interest}

The authors have nothing to declare. 


\section{References}

1. Oaseem A, Wilt TJ, Weinberger SE, et al. Diagnosis and management of stable chronic obstructive pulmonary disease: a clinical practice guideline update from the American College of Physicians, American College of Chest Physicians, American Thoracic Society, and European Respiratory Society. Ann Intern Med. 2011;155:179-191. doi: https://doi.org/10.7326/0003-4819-155-3-201108020-00008

2. Woodruff PG, Barr RG, Bleecker E, et al. Clinical significance of symptoms in smokers with preserved pulmonary function. $N$ Engl $J$ Med. 2016;374:1811-1821.

doi: https://doi.org/10.1056/NEJMoa1505971

3. Rodriguez-Roisin R, Han MK, Vestbo J, et al. Chronic respiratory symptoms with normal spirometry. A reliable clinical entity? Am J Respir Crit Care Med. 2017;195(1):17-22.

doi: https://doi.org/10.1164/rccm.201607-1376PP

4. Martinez $\mathrm{CH}$, Diaz AA, Meldrum C, et al. Age and small airway imaging abnormalities in subjects with and without airflow limitation in SPIROMICS. Am J Respir Crit Care Med. 2017; 195(4):464-472. doi: https://doi.org/10.1164/rccm.201604-0871OC

5. Regan EA, Lynch DA, Curran-Everett D, et al. Clinical and radiologic disease in normal smokers with normal spirometry. JAMA Intern Med. 2015;175(9):1539-1549.

doi: https://doi.org/10.1001/jamainternmed.2015.2735

6. Bowler RP, Kim V, Regan E, et al. Prediction of acute respiratory disease in current and former smokers with and without COPD. Chest. 2014;146(4):941-950.

doi: https://doi.org/10.1378/chest.13-2946

7. Jones PW, Harding G, Berry P, et al. Development and first validation of the COPD Assessment Test. Eur Respir J. 2009;34(3):648-654. doi: https://doi.org/10.1183/09031936.00102509

8. Hoesterey D, Das N, Janssens W, et al. Spirometric indices of early airflow limitation in individuals at risk of developing COPD: spirometry beyond FEV1/FVC. Respir Med. 2019; 156:58-68. doi: https://doi.org/10.1016/j.rmed.2019.08.004

9. Miller MR, Hankinson JL, Brusaco V, et al. Standardization of spirometry. Eur Respir J. 2005;26 (2):319-338. doi: https://doi.org/10.1183/09031936.05.00034805

10. Morris J, Koski A, Johnson LC. Spirometric standards for healthy nonsmoking adults. Am Rev Respir Dis.1971;103(1):57-67. doi: https://doi.org/10.1097/00043764-197107000-00021

11. Knudson RJ, Slatin RC, Lebowitz MD, et al. The maximal expiratory flow-volume curve. Normal standards, variability, and effects of age. Am Rev Respir Dis.1976;113(5):587-600.

12. Hankinson JL, Odencrantz JR, Fedan KB. Spirometric reference values from a sample of the general United States population. Am J Respir Crit Care Med. 1999;159(1):179-187. doi: https://doi.org/10.1164/ajrccm.159.1.9712108
13. Burrows B, Kasik J, Niden A, et al. Clinical usefulness of the singlebreath pulmonary diffusing capacity test. Am Rev Respir Dis. 1961;84(6):789-806.

14. Goldman HI, Becklake MR. Normal values at median altitudes and the prediction of normal results. Am Rev Respir Dis. 1959;79(4):45767.

15. Zarins LP, Clausen JL. In Clausen JL, Eds. Pulmonary Function Testing, Guidelines, and Controversies. Academic Press, 1982:141153.

16. Thurlbeck WM, Muller NL. Emphysema: definition, imaging and quantification. Am J Roent. 1994; 163(5):1017-1025. doi: https://doi.org/10.2214/ajr.163.5.7976869

17. Gelb AF, Hogg JC, Muller NL, et al. Contribution of emphysema and small airways in COPD. Chest. 1996;109(2):353-359. doi: https://doi.org/10.1378/chest.109.2.353

18. Gelb AF, Schein MJ, Kuei J, et al. Limited contribution of emphysema in advanced chronic obstructive pulmonary disease. Am Rev Respir Dis. 1994;147(5):1157-1161.

doi: https://doi.org/10.1164/ajrccm/147.5.1157

19. Thurlbeck WM. Measurement of pulmonary emphysema. Am Rev Respir Dis.1966;95(5):752-764.

20. Quanjer PH, Stanojevic S, Cole TJ, et al. Global Lung Function Initiative. Multi-ethnic reference values for spirometry for the 3-95year age range. The Global Lung Function 2012 equations. Eur Respir J. 1993;6 (Supplement 16): 5-40.

doi: https://doi.org/10.1183/09031936.00080312

21. Fabbri LM. Smoking, not COPD, as the disease. $N$ Engl $J$ Med. 2016;374(19):1885-1886.

doi: https://doi.org/10.1056/NEJMe1515508

22. Global Initiative for Chronic Obstructive Disease (GOLD). Global strategy for the diagnosis, management, and prevention of chronic obstructive pulmonary disease, 2016 report. GOLD website. Published 2016. Accessed September 2020. https:/ /www.goldcopd.org

23. Woolcock AJ, Vincent NJ, Macklem PT. Frequency dependence of compliance as a test for obstruction in small airways. J Clin Invest. 1969;48(6):1097-1106. doi: https://doi.org/10.1172/JCI106066

24. Mead J. The lung's "quiet zone." N Engl J Med. 1970;282(23):13181319. doi: https://doi.org/10.1056/NEJM197006042822311

25. Hogg JC, Williams J, Richardson JB, et al. Age as a factor in the distribution oflower airway conductance and in the pathologic anatomy of obstructive lung disease. N Engl J Med. 1970; 282(23):1283-1287. doi: https://doi.org/10.1056/NEJM197006042822302

$\overline{\text { 26. Levine G, Housley F, Macleod P, et al. Gas exchange abnormalities }}$ in mild bronchitis and asymptomatic asthma. $N$ Engl $J$ Med. 1970;282(23):1277-1282.

doi: https://doi.org/10.1056/NEJM197006042822301 
27. Macklem PT, Mead J. Resistance of central and peripheral airways measured by a retrograde catheter. J Appl Physiol. 1967; 22(3):395401. doi: https://doi.org/10.1152/jappl.1967.22.3.395

28. Hogg JC, Macklem PT, Thurlbeck WM. Site and nature of airway obstruction in chronic obstructive lung disease. N Engl J Med. 1968; 278(25):1355-1360.

doi: https://doi.org/10.1056/NEJM196806202782501

29. Gelb AF, Gold WM, Wright RR, et al. Physiologic diagnosis of subclinical emphysema. Am Rev Respir Dis. 1973; 107(1):50-63. doi: https://doi.org/10.1164/arrd.1973.107.4.571

30. Zamel N, Hogg J, Gelb A. Mechanisms of maximal expiratory airflow limitation in clinically unsuspected emphysema and obstruction of the peripheral airways. Am Rev Respir Dis. 1976;113(3):337-344.

31. Gelb AF, Zamel N. Simplified diagnosis of small-airway obstruction. N Engl J Med. 1973;288(8):395-398. doi: https://doi.org/10.1056/NEJM197302222880805

32. Fry DL, Hyatt RE. Pulmonary mechanics. A unified analysis of the relationship between pressure, volume and gas flow in the lungs of normal and diseased subjects. Am J Med. 1960; 29(4):672-689. doi: https://doi.org/10.1016/0002-9343(60)90100-5

33. Hutcheon M, Griffin P, Levison $\mathrm{H}$, et al. Volume of isoflow. A new test in detection of mild abnormalities of lung mechanics. Am Rev Respir Dis. 1974; 110(4):458-465.

34. Pride NB, Permutt S, Riley RL, et al. Determinants of maximal expiratory flow from the lungs. J Appl Physiol. 1967;23(5):646-662. doi: https://doi.org/10.1152/jappl.1967.23.5.646

35. Mead J, Turner JM, Macklem PT, et al. Significance of the relationship between lung recoil and maximum expiratory flow. J Appl Physiol. 1967;22(1):95-108.

doi: https://doi.org/10.1152/jappl.1967.22.1.95

36. Cosio M, Ghezzo H, Hogg JC, et al. The relationship between structural changes in small airways and pulmonary function tests. $N$ Engl $J M e d$. 1977;298(23):1277-1281.

doi: https://doi.org/10.1056/NEJM197806082982303

37. Hogg JC, Chu F, Utokaparch S, et al. The nature of small-airway obstruction on chronic obstructive pulmonary disease. $N$ Engl $\mathrm{J}$ Med. 2004;350(26):2645-2653.

doi: https://doi.org/10.1056/NEJMoa032158

38. McDonough JE, Yuan R, Suzuki M, et al. Small-airway obstruction and emphysema in chronic obstructive pulmonary disease. $N$ Engl $J$ Med. 2011;365(17):1567-1575.

doi: https://doi.org/10.1056/NEJMoa1106955

39. Hogg JC, Wright JL, Wiggs BR, et al. Lung structure and function in cigarette smokers. Thorax. 1994;49(5):473-478.

doi: https://doi.org/10.1136/thx.49.5.473
40. Tan WC, Hague CJ, Leipsic J, et al. Findings on thoracic computed tomography scans and respiratory outcomes in persons with and without chronic obstructive pulmonary disease: a population-based cohort study. PLoS ONE. 2016; 1(11):e0166745. doi: https://doi.org/10.1371/journal.pone.0166745

41. Hogg JC, Pare PD, Hackett TL. The contribution of small airway obstruction to the pathogenesis of chronic obstructive pulmonary disease. Physiol Rev. 2017; 97(2):529-552. doi: https://doi.org/10.1152/physrev.00025.2015

42. Stanojevic S, Wade A, Stocks J. Reference ranges for spirometry across all ages: a new approach. Am J Respir Crit Care Med. 2008;177(3):253260. doi: https://doi.org/10.1164/rccm.200708-12480C

43. Gelb AF, Williams AJ, Zamel N. Spirometry: FEV1 vs FEF25-75 Percent. Chest. 1983; 84(4):473-474. doi: https://doi.org/10.1378/chest.84.4.473

44. Morris ZQ, Coz B, Starosta D. An isolated reduction of the FEV3/FVC ratio is an indication of mild lung injury. Chest. 2013;144(4):11171123. doi: https://doi.org/10.1378/chest.12-2816

45. Dilektasil AG, Porszasz J, Casaburi R, et al. A novel spirometric measure identifies mild COPD unidentified by standard criteria. Chest. 2016;150(5):1080-1090.

doi: https://doi.org/10.1016/j.chest.2016.06.047

46. Gelb AF, Yamamoto A, Verbeken EK, et al. Further studies of unsuspected emphysema in non-smoking asthmatics with persistent expiratory airflow obstruction. Chest. 2018;153(3):618-629. doi: https://doi.org/10.1016/j.chest.2017.11.016

47. ATS 2017 Documents. Recommendations for a standardized pulmonary function report. Am J Respir Crit Care Med. 2017;196(11): 1463-1472. doi: https://doi.org/10.1164/rccm.201701-0164UP

48. Quanjer PH, Weiner DJ, Pretto JJ, et al. Measurement of FEF25-75\% or the FEF $75 \%$ does not contribute to clinical decision making. Eur Respir J. 2014; 43:1051-1058. doi: https://doi.org/10.1183/09031936.00128113

49. Lukic KZ, Coates AL. Does the FEF25-75 or the FEF75 have any value in assessing lung disease in children with cystic fibrosis or asthma? Pediatr Pulmonol. 2015;50:863-868.

doi: https://doi.org/10.1002/ppul.23234

50. Knudson RJ, Burrows B, Lebowitz MD. The maximal expiratory flowvolume curve: Its use in the detection of ventilatory abnormalities in a population study. Am Rev Respir Dis. 1976;14:(5)671-879.

51. Peters JM, Ferris BG Jr. Smoking, pulmonary function and respiratory symptoms in a college-age group. Am Rev Respir Dis. 1967;95:(5):774782.

52. Seely JE, Zuskin E, Bouhuys A. Cigarette smoking: objective evidence for lung damage in teen-agers. Science.1971;172(3984):741-743. doi: https://doi.org/10.1126/science.172.3984.741 
53. McFadden ER Jr Resurrection men and the FEF25-75\%. J Allergy Clin Immunol. 2010;126:535-536.

doi: https://doi.org/10.1016/j.jaci.2010.06.035

54. Sator L, Horner A, Studnicka, Lamprecht, Kaiser B, McBurnie MA, et al. Overdiagnosis of COPD in subjects with unobstructed spirometry. A BOLD analysis. Chest. 2019;156(2):277-288.

doi: https://doi.org/10.1016/j.chest.2019.01.015

55. Vanfleteren LEGW, Andersson AE, Fabbri LM. COPD: What's in a name? Mismatch of diagnostic labels and required physiologic features. Chest. 2019;156(2):195-196.

doi: https://doi.org/10.1016/j.chest.2019.05.008

56. Singh D, Augusti A, Anzueto A, et al. Global strategy for the diagnosis, management, and prevention of chronic obstructive pulmonary disease: the GOLD Science Committee Report 2019. Eur Respir J. 2019;53(5): 1900164.

doi: https://doi.org/10.1183/13993003.00164-2019

57. Lowe KE, Regan EA, Anzueto A et al. COPDGene 2019: redefining the the diagnosis of chronic obstructive pulmonary disease. Chronic Obstr Pulm Dis. 2019;(5):384-399.

58. Barnes PJ, Vestbo J, Calverley PM. The pressing need to redefine "COPD." Chronic Obstr Pulm Dis. 2019;6(5):380-383.

doi: https://doi.org/10.15326/jcopdf.6.5.2019.0173 